\title{
Outsourcing Under Incomplete Information
}

\author{
Tarun Kabiraj \\ Email: tarunkabiraj@hotmail.com \\ Economic Research Unit \\ Indian Statistical Institute
}

Uday Bhanu Sinha

Email: uday@econdse.org

Department of Economics

Delhi School of Economics

\section{Working Paper No. 272}

http://www.cdedse.org/pdf/work272.pdf

\section{CENTRE FOR DEVELOPMENT ECONOMICS}

DELHI SCHOOL OF ECONOMICS 


\title{
Outsourcing under Incomplete Information*
}

\author{
Tarun Kabiraj a, , Uday Bhanu Sinha ${ }^{\mathrm{b}}$ \\ a Economic Research Unit, Indian Statistical Institute, 203 B. T. Road, Kolkata - 700108 \\ ${ }^{b}$ Department of Economics, Delhi School of Economics, University of Delhi, Delhi - 110007
}

Version: March 2017

\begin{abstract}
We consider outsourcing decision of a firm in a Cournot duopoly with incomplete information. There is incomplete information about the production technology of one firm. It is shown that outsourcing can occur as outcomes of a separating or pooling perfect Bayesian equilibrium, although it is not profitable under complete information. Thus, our paper shows that asymmetric information can itself be a reason for outsourcing. We further show that under outsourcing equilibrium consumers gain, producers as a whole loose, but the overall welfare falls.
\end{abstract}

Keywords: Outsourcing, incomplete information, Bayesian Cournot, signalling and pooling equilibrium, welfare analysis.

JEL Classifications: D43; L22; L23.

*Correspondence to: Tarun Kabiraj, Economic Research Unit, Indian Statistical Institute, 203 B. T. Road, Kolkata 700108, India. Fax: (91) (33) 25778893.

Email: <Tarun Kabiraj> tarunkabiraj@hotmail.com; <Uday Bhanu Sinha> uday@econdse.org

Acknowledgement: Both authors would like to express their gratitude to Prabal Roy Chowdhury for very helpful comments and suggestions on the earlier version of the paper. 


\section{Introduction}

Outsourcing is a widespread and growing phenomenon in modern business, having increased over 30\% per annum over the last two decades. Such outsourcing can happen not just locally, but even globally. If anything, global sourcing is increasing at an even faster pace. For instance, while only $10 \%$ of U.S. firms were engaged in global sourcing in 2000, by 2007 the number had risen to $50 \%$ (Lewin and Couto, 2007).

Such outsourcing is of particular interest to developing countries, given that some of them appear to be hubs of business process outsourcing. For instance, U.S. firms have offshored mainly to India (50\% of projects), Latin America (11\%), China (9\%) and other Asian countries $(11 \%) .{ }^{1}$ In software and BPO industries India remains a preferred destination. According to the National Association of Software \& Service Companies (NASSCOM), almost half of all Fortune 500 companies choose to outsource software development to India. Even though there is competition from other countries (including China, Mexico, Ireland and the Philippines), India has managed to remain the top outsourcing destination.

Interestingly such outsourcing is not a one-way street, with even firms from developing countries beginning to outsource their production. Recently some of the biggest and the best Indian companies have begun to outsource their IT services to global firms. For instance, under the Bank of India - Hewlett-Packard (HP) deal -- a contract valued over $\$ 150$ million $^{2}$-- HP is to supply information technology infrastructure and applications over 10 years. Accenture has agreed to manage Dabur's IT functions for supply chain and secondary sales functions. Relatedly, the Manipal Academy of Higher Education has signed a memorandum of understanding with Hewlett-Packard India Sales to enhance the campus computing experience of students. In the automotive industry, Indian vehicle manufacturers are outsourcing more and more of their components, rather than producing them in house.

One reason that developing countries attract so much outsourcing is of course because of their relative cost advantages. One source of such low costs is the fact that many developing countries possess a huge pool of qualified science and engineering graduates (Lewin et al., 2009; Manning et al. 2008), making sourcing from developing countries very attractive given

\footnotetext{
${ }^{1}$ See Manning (2013) for details.

${ }^{2}$ See http://www.rediff.com/money/2004/mar/15bpo.htm.
} 
the low wages in these countries (Lewin and Peeters, 2006). But it is important to understand that cost differentials cannot be the only consideration while deciding whether to outsource or not, since in an imperfectly competitive market the outsourcing decision also involves a significant strategic component, so that a firm may outsource crucial inputs even when its inhouse production is less expensive. ${ }^{3}$ There is now a growing literature that focuses on the strategic reasons for outsourcing with the essential idea being that in an oligopoly setup, the firms can use the outsourcing option in a bid to influence the reaction functions in a manner that helps the outsourcing firm.

The literature has examined several reasons for outsourcing. Some studies have focussed on the existence of scale economies in input production and found that it is better for the final goods producers to outsource the inputs from the common input supplier (Shy and Stenbacka, 2003; Buehler and Haucap, 2006). ${ }^{4}$ Arya et al. (2008) considered how outsourcing by a final good producer increases its competitiveness by raising the input prices for its rival. Chen (2011) shows that the outsourcing decision of an incumbent might prevent entry of a potential entrant as the incumbent can commit to an aggressive post-entry competition. Kabiraj and Sinha (2014 and 2016) argue that technology transfer can be a motive for outsourcing. They consider a final good producer which has a superior input-production technology to that of the independent input supplier. The final good producer then transfers its technology to the independent input supplier by means of patent sale and thereby commits to outsourcing. ${ }^{5}$ Surprisingly though, all studies on outsourcing adopt a complete information framework. The role of incomplete or asymmetric information as a possible reason for strategic outsourcing is never identified in the literature. The present paper is an attempt to fill this gap and raise the issue of outsourcing in an incomplete information environment.

Consideration of incomplete information in the context of outsourcing decision is natural in view of the fact that a firm taking the decision regarding whether to 'outsource or not', interacts with the other firms in an oligopolistic framework, and some of these firms often possess

\footnotetext{
${ }^{3}$ For example, during 2000s the aircraft giant Boeing had entered into a series of outsourcing agreements with three Japanese firms (Mitsubishi Heavy Industries, Kawasaki Heavy Industries Ltd., and Fuji Heavy Industries) regarding supply of some goods related to aircraft production, including R\&D. However, it was observed that costs of these goods in Japan were no less, hence Boeing's outsourcing decision cannot be justified based on costsaving. Outsourcing contracts between Boeing and Lockheed is another example (see Chen, 2011).

${ }^{4}$ Sinha (2016) re-examines the role of economies of scale in Cournot competition and shows that the existence of outsourcing equilibrium crucially depends on the existence of input supplier given its fixed cost.

${ }^{5}$ Though the above papers are concerned with the strategic motives behind outsourcing in closed economy models, there are some interesting papers which analyze the strategic effects of international outsourcing. See Beladi et al. (2012), Marjit and Mukherjee (2008), and Pack and Saggi (2001), among others.
} 
private information about some characteristics relevant for production decision. For instance, a firm may not know the rival's production technology, or it may not know the quality of the inputs it will be outsourcing. In general, it may not know the rival's type. Such asymmetry of information should influence the decision of the firm.

In the present paper we construct a model of two firms interacting in the product market under asymmetric information where both firms have the option of either producing the inputs inhouse, or buying the inputs from an input market, and one firm has private information about its technological capability. However, using outsourced inputs (which are substitute to inputs produced in-house) involves a fixed cost at the plant level. It requires setting up new plant or machines to make the outsourced input convertible or appropriately usable, given the production technology.

We assume that the firm with private information can be one of two types, viz., high cost or low cost. To focus on the role of incomplete information on the choice of outsourcing, we examine a scenario such that under complete information neither type will go for outsourcing, given the fixed cost associated with it. Interestingly however, under incomplete information, depending on the size of the fixed cost, either the low cost type firm, or both types will opt for outsourcing inputs in equilibrium. We portray situations when a separating equilibrium exists under which the low cost type outsources inputs and the high cost type produces inputs inhouse. On the other hand, there also exists a pooling equilibrium where both high and low types outsource inputs in equilibrium. This happens when the fixed cost associated with outsourcing is small. Actually, the high cost firm pools with the low cost type and gains from the fact that the rival firm behaves less aggressively since it is not sure how efficient its competitor is. We also argue that a separating equilibrium with high cost firm outsourcing inputs and the low cost firm producing inputs in-house will never arise.

Thus our paper shows that simply the presence of incomplete information about the type of one interacting firm may motivate it to go for outsourcing. In particular, the existence of a separating equilibrium demonstrates that outsourcing can be used as signal of production technology. Finally, we provide a welfare analysis under incomplete information vis-à-vis the case of complete information. We show that under outsourcing equilibrium the consumers gain and producers as a whole loose, but the overall welfare falls unambiguously.

The next section describes the model and derives the results of the paper. Then section 3 provides a brief welfare analysis and section 4 concludes the paper. 


\section{Model}

Consider two firms, call them firm 1 and firm 2, which compete a la Cournot in a market for a homogenous good. While firm 1's type is deterministic, firm 2's type is random; thus firm 2 can either be high cost, denoted the H type, or low cost, denoted the L type.

We assume the following technological specifications. The production technology of each of firm 1 and the $\mathrm{H}$ type of firm 2 involves transforming a single input into the output, but the $\mathrm{L}$ type of firm 2's technology requires $\alpha(<1)$ units of inputs to produce one unit of output. The firms can either produce the input in-house, or outsource an input substitute from an external input market. However, production using outsourced inputs involves a fixed cost, $F>0$. This is required for altering the existing plant or to set up a new plant so that the outsourced input is accommodated in the final good production process. Thus, F represents the plant level adjustment cost for using the outsourced inputs, and this is over and above the cost of procuring the input from the market. If the firms decide to produce the input in-house, then no such additional cost is required for production, but there is a marginal cost of in-house input production.

Let the per unit outsourced input cost be $c_{H}$. If inputs are produced in-house, the per unit cost of input production by firm 1 and the $\mathrm{H}$ type of firm 2 are respectively $c$ and $c_{H}$, with $0 \leq c<$ $c_{H}$. Then given their technologies, if inputs are produced in-house, the per unit final good production by firm 1 and the $\mathrm{H}$ type of firm 2 are also, respectively, $c$ and $c_{H}$, whereas if inputs are outsourced, each of them will have a per unit production $\operatorname{cost}$ of $c_{H}$.

On the other hand, given the L type firm 2's technology, if it produces inputs in-house, let its per unit cost of final good production be $c_{L}<c_{H}$, that is, its in-house input production cost is $\left(c_{L} / \alpha\right)$. Since it can outsource input at a cost of $c_{H}$ per unit, then under outsourcing its per unit cost of final good is $\alpha c_{H}$. We assume $\alpha c_{H} \geq c_{L}$. ${ }^{6}$ So $\mathrm{L}$ type has a lower cost of production vis-à-vis the $\mathrm{H}$ type.

Finally, the market demand function is assumed to be linear and is given by

$$
P=a-\left(X_{1}+X_{2}\right) ; a>c_{H} \text {, }
$$

\footnotetext{
${ }^{6}$ By this we rule out the possibility of outsourcing based on cost consideration.
} 
where $P$ is the price of the final good and $X_{i}$ is the quantity of the good supplied by firm $i(i=$ $1,2)$.

We consider the following game. In stage 1 , nature chooses the type of firm 2 , with type $\mathrm{H}$ being chosen with probability $\theta$, and type $\mathrm{L}$ with probability $1-\theta$, where this choice is private information of firm 2. In stage 2, both firms simultaneously choose whether to outsource the input, or produce the input in-house. However, we have restricted the parameters in a manner that firm 1 would never choose outsourcing in equilibrium. In stage 3 , they compete in the final good market a la Cournot.

\subsection{Complete Information Scenario}

Firm 2's type will be perfectly observable to firm 1 under complete information. Firm 1's unit cost of production is $c$. Suppose firm 2 is a high cost firm, hence its unit cost of production, both under in-house input production and outsourcing, is $c_{H}$. Therefore, under complete information, assuming $c_{H}<\frac{a+c}{2}$ (so that the high cost firm produces a positive output), the payoffs of the $\mathrm{H}$ type of firm 2 under in-house production $(I)$ and outsourcing $(O)$ are respectively,

$$
\pi_{H}^{I}=\left(\frac{a-2 c_{H}+c}{3}\right)^{2} \text { and } \pi_{H}^{O}=\left(\frac{a-2 c_{H}+c}{3}\right)^{2}-F .
$$

In case firm 2 is known to be a low cost firm, then the L type firm 2's payoffs under in-house production and outsourcing are respectively,

$$
\pi_{L}^{I}=\left(\frac{a-2 c_{L}+c}{3}\right)^{2} \quad \text { and } \quad \pi_{L}^{O}=\left(\frac{a-2 \alpha c_{H}+c}{3}\right)^{2}-F
$$

Proposition 1: Under complete information neither type of firm 2 will opt for outsourcing inputs.

This is obvious from (2) and (3), given $F>0$ and $\alpha c_{H} \geq c_{L}$. Actually, we frame the parameter values in such a way that outsourcing by any firm does not occur under complete information. However, we show below that for the same parameter values outsourcing will occur under incomplete information. 


\subsection{Incomplete Information Scenario}

While firm 1's production technology is always common knowledge, recall that firm 2's production technology (determining unit cost of production) is determined by nature in the first stage of the game and is revealed only to firm 2 . Thus, firm 2 has private information about its unit cost of production $\left(c_{H}\right.$ or $\left.c_{L}\right)$ in the beginning of stage 2 of the game. However, firm 1 does not know that information but holds some prior belief about the types of firm 2 . Let us assume that the prior belief of firm 1 is that firm 2 is of high cost type with probability $\theta, 0 \leq \theta \leq 1$, and of low cost type with probability $(1-\theta)$. All these are common knowledge.

First, suppose that the option of outsourcing of inputs is not available to firm 2 as an alternative to in-house input production. Then under incomplete information the Bayesian Nash equilibrium quantities are (see Gibbons, 1992)

$$
X_{1}^{*}=\frac{a-2 c+\theta c_{H}+(1-\theta) c_{L}}{3}, X_{H}^{*}=\frac{a-2 c_{H}+c}{3}+\frac{(1-\theta)\left(c_{H}-c_{L}\right)}{6}, X_{L}^{*}=\frac{a-2 c_{L}+c}{3}-\frac{\theta\left(c_{H}-c_{L}\right)}{6},
$$

where $X_{H}^{*}$ and $X_{L}^{*}$ are the quantities of two types of firm 2 under Bayesian Nash equilibrium.

The corresponding payoffs of firm 2 depending on type are,

$$
\pi_{H}^{*}=\left(\frac{a-2 c_{H}+c}{3}+\frac{(1-\theta)\left(c_{H}-c_{L}\right)}{6}\right)^{2} \text { and } \pi_{L}^{*}=\left(\frac{a-2 c_{L}+c}{3}-\frac{\theta\left(c_{H}-c_{L}\right)}{6}\right)^{2} .
$$

Clearly, we have by comparing with (2) and (3),

$$
\pi_{H}^{*}>\pi_{H}^{I} \quad \text { and } \quad \pi_{L}^{*}<\pi_{L}^{I}
$$

Therefore, without the possibility of outsourcing under incomplete information, the high cost firm gains and the low cost firm suffers a loss compared to complete information situation, and the loss (gain) of the low (high) cost firm increases (decreases) as $\theta$ goes up. Therefore, the high cost type firm 2 has no incentive to reveal its cost type to the rival. But the low cost type firm 2 has an incentive to reveal its type. If the low cost firm 2 could convince firm 1 that it is indeed a low cost firm and if firm 1 would believe it with probability one, then the low cost firm 2's profit could be higher than $\pi_{L}^{*}$. In other words, in a standard Bayesian Cournot equilibrium with one sided asymmetric information, one type gains and the other type loses due to asymmetric information since the rival firm, without knowing that information, would always choose his output as a reaction based on the expected output that would be produced by firm 2 under complete information. This brings us to the point to explore whether the losing 
type of firm 2 can credibly signal its type by choosing its mode of sourcing input in stage 2 of the game and improve its payoff.

Now we consider the possibility of outsourcing inputs from the input market as an alternative to in-house production to be chosen at stage 2 of the game. Then our question is: Can the low cost firm 2 signal its type by outsourcing? Since outsourcing involves a fixed cost, signalling may not be always possible. So we first derive the condition(s) under which a separating equilibrium exists where the low cost type firm 2 opts for outsourcing, whereas the high cost type firm 2 continues with in-house input production. We then explore the possibility of pooling equilibrium on outsourcing, that is, in equilibrium both types prefer outsourcing. We also show that separating equilibrium with high cost type firm outsourcing cannot arise. ${ }^{7}$

For the remainder of the analysis, to simplify the algebra we assume

$$
\alpha c_{H}=c_{L}
$$

This is for expositional purposes only, and all our results follow if we do not make this assumption. This would require some further restrictions on $\alpha$ of course.

There are different combinations of choices possible for firm 2 at stage 2 depending on its type. Below we examine a separating equilibrium where the high cost type firm 2 chooses in-house production (I), and the low cost type firm 2 chooses outsourcing $(\mathrm{O})$.

\section{Case 1: (In-house, Outsourcing) as a separating equilibrium}

This is the most important scenario because in a separating equilibrium the low cost firm can signal its type convincingly. Under this equilibrium the belief of firm 1 will be the following. If firm 2 is observed to outsource, it is believed to be the low cost type with probability one, and if firm 2 opts for in-house production it is believed to be the high cost type, that is, $\mu(L \mid O)=1=\mu(H \mid I)$. Then along the equilibrium path, the payoffs of $\mathrm{H}$ and $\mathrm{L}$ will be, respectively,

$$
\pi_{H}^{(I, O)}=\left(\frac{a-2 c_{H}+c}{3}\right)^{2} \text { and } \pi_{L}^{(I, O)}=\left(\frac{a-2 c_{L}+c}{3}\right)^{2}-F .
$$

\footnotetext{
${ }^{7}$ Although in this paper we are not interested in pooling on in-house production by both types in equilibrium, but one may easily check that such an equilibrium exists if the fixed cost associated with outsourcing is above a critical level, and this can be supported by an appropriate off-the-equilibrium belief.
} 
Now, for (In-house, Outsourcing) to be a separating equilibrium we need to ensure that the neither type of firm 2 has any incentive to deviate. Given the above beliefs, we can check (see Appendix A) that the defection payoffs of $\mathrm{H}$ and $\mathrm{L}$ will be respectively,

$$
\hat{\pi}_{H}^{(I, O)}=\left(\frac{a-2 c_{H}+c}{3}+\frac{c_{H}-c_{L}}{6}\right)^{2}-F \quad \text { and } \quad \hat{\pi}_{L}^{(I, O)}=\left(\frac{a-2 c_{L}+c}{3}-\frac{c_{H}-c_{L}}{6}\right)^{2} .
$$

Therefore, for separating equilibrium the following two conditions must be satisfied simultaneously, that is,

$$
\begin{array}{r}
\pi_{H}^{(I, O)}>\hat{\pi}_{H}^{(I, O)} \Leftrightarrow F>\left(\frac{a-2 c_{H}+c}{3}+\frac{c_{H}-c_{L}}{6}\right)^{2}-\left(\frac{a-2 c_{H}+c}{3}\right)^{2} \equiv \underline{F}^{O}, \\
\text { and } \pi_{L}^{(I, O)}>\hat{\pi}_{L}^{(I, O)} \Leftrightarrow F<\left(\frac{a-2 c_{L}+c}{3}\right)^{2}-\left(\frac{a-2 c_{L}+c}{3}-\frac{c_{H}-c_{L}}{6}\right)^{2} \equiv \bar{F}^{O},
\end{array}
$$

it is straightforward to check that $0<\underline{F}^{O}<\bar{F}^{O}$. Of course firm 1 has no incentive to outsource. Hence we can write the following proposition.

Proposition 2: For all $F \in\left(\underline{F}^{O}, \bar{F}^{O}\right)$, a separating Perfect Bayesian equilibrium exists where the high cost firm 2 chooses to produce its inputs in-house and the low cost firm 2 chooses outsourcing and firm 1 holds the belief that $\mu(H \mid I)=\mu(L \mid O)=1$.

Therefore, when the fixed cost associated with outsourcing inputs is neither too small nor too high, the low cost firm 2 can credibly signal its type to its rival firm 1 . Here outsourcing is acting as signal. Given the cost structure the high cost firm cannot mimic as low cost firm, that's why firm 1 is fully convinced about firm 2's type.

Note that in our paper under incomplete information the firm with the private information has the option of signalling only through the choice of mode of production organization. Outsourcing is chosen as a signal by the efficient type of firm 2 when the cost of doing so (that is, F), is neither too high nor too low. This signalling is like burning money to convince the rival that its variable cost of production is low, and when this is credible the rival firm 1 would react by scaling down its production as it is convinced of competing with the low cost type firm 2. Thus our proposition establishes that outsourcing can be a signal of the firm's type.

We next turn to examining pooling equilibria. 
Case 2: (Outsourcing, Outsourcing) as a polling equilibrium

Consider the following strategies and beliefs of the firms under this equilibrium. When outsourcing occurs by firm 2, firm 1 will have belief that firm 2 is of the high cost type with probability $\theta$, and is of the low cost type with probability $(1-\theta)$, that is, the prior belief will remain as the posterior. Therefore, under equilibrium strategy, the payoffs of the two types of firm 2 are

$$
\pi_{H}^{(O, O)}=\pi_{H}^{*}-F \quad \text { and } \quad \pi_{L}^{(O, O)}=\pi_{L}^{*}-F
$$

Now consider the off-the-equilibrium beliefs. Assume that firm 1's belief is that only the high cost type firm 2 can deviate, if at all, hence $\mu(H \mid I)=1=1-\mu(L \mid I)$. With this belief firm 2's deviation payoffs are

$$
\hat{\pi}_{H}^{(O, O)}=\left(\frac{a-2 c_{H}+c}{3}\right)^{2} \quad \text { and } \quad \hat{\pi}_{L}^{(O, O)}=\left(\frac{a-2 c_{L}+c}{3}-\frac{c_{H}-c_{L}}{6}\right)^{2} .
$$

Therefore, for (Outsourcing, Outsourcing) to be a pooling equilibrium, the following two conditions must have to be simultaneously satisfied, that is,

$$
\begin{gathered}
\pi_{H}^{(O, O)}>\hat{\pi}_{H}^{(O, O)} \Leftrightarrow F<\left(\frac{a-2 c_{H}+c}{3}+\frac{(1-\theta)\left(c_{H}-c_{L)}\right.}{6}\right)^{2}-\left(\frac{a-2 c_{H}+c}{3}\right)^{2} \equiv \underline{F}^{O O}, \\
\text { and } \pi_{L}^{(O, O)}>\hat{\pi}_{L}^{(O, O)} \Leftrightarrow F<\left(\frac{a-2 c_{L}+c}{3}-\frac{\theta\left(c_{H}-c_{L}\right)}{6}\right)^{2}-\left(\frac{a-2 c_{L}+c}{3}-\frac{c_{H}-c_{L}}{6}\right)^{2} \equiv \bar{F}^{O O} .
\end{gathered}
$$

We can simplify to get

$$
\underline{F}^{O O}=2 \frac{\left(a-2 c_{H}+c\right)}{3} \frac{(1-\theta)\left(c_{H}-c_{L}\right)}{6}+\left(\frac{(1-\theta)\left(c_{H}-c_{L)}\right.}{6}\right)^{2},
$$

and $\bar{F}^{O O}=2 \frac{\left(a-2 c_{L}+c\right)}{3} \frac{(1-\theta)\left(c_{H}-c_{L}\right)}{6}-\left(1-\theta^{2}\right)\left(\frac{c_{H}-c_{L}}{6}\right)^{2}$.

Finally, since $\bar{F}^{O O}>\underline{F}^{O O}$ holds, therefore (Outsourcing, Outsourcing) can be sustained as a polling equilibrium for all $F<\underline{F}^{O O}$. To write it formally,

Proposition 3: For all $F<\underline{F}^{\text {Oo }}$, a pooling Perfect Bayesian equilibrium exists in which both high cost and low cost types of firm 2 choose outsourcing and firm 1 holds belief that $\mu(H \mid O)=$ $\theta$ and $\mu(L \mid O)=(1-\theta)$ on the equilibrium path, along with off-the-equilibrium belief that $\mu(H \mid I)=1$.

Note that under this equilibrium both types of firm 2 are choosing to outsource, so that the low cost firm 2 is not able to separate out from the high cost firm 2. However, given the off-the- 
equilibrium belief held by firm 1, it is not worthwhile for the low cost firm 2 to choose the other option of in-house production for this parameter range. This equilibrium is happening for low values of F. Hence, the high cost type does not mind the extra fixed cost of plant adjustment and pool with the low cost type firm 2 in order to take advantage of the extra profit that it earns in a Cournot Bayesian equilibrium. ${ }^{8}$

Note that the incidence of outsourcing occurs in our model for two different reasons, both related to the presence of incomplete information. On the one hand, given the extra cost of outsourcing, outsourcing acts as a signal and thereby a separating equilibrium is obtained. On the other hand, when there is no possibility of signalling due to the possibility of mimicking by the high cost type firm 2, outsourcing is chosen by the low cost type firm 2 to ensure that firm 1 does not take an aggressive stance which holds the belief that in case the in-house production is undertaken, it must be the high cost type firm 2. Given the choice of outsourcing by the low cost firm 2, the high cost firm 2 also finds it preferable to outsource given that the fixed cost is low. The high cost type firm 2 goes for outsourcing to avoid the adverse off-the equilibrium belief of the rival. In contrast, under complete information outsourcing is not sustained as a subgame perfect equilibrium outcome.

Before we conclude this section, we show that there is no separating equilibrium in which the high cost firm alone outsources. For (Outsourcing, In-house) to be an equilibrium, along the equilibrium path the belief must be $\mu(H \mid O)=1=\mu(L \mid I)$. Under this belief if an equilibrium exists, then the payoffs of the high cost and low cost type firm 2 would be

$$
\pi_{H}^{(O, I)}=\left(\frac{a-2 c_{H}+c}{3}\right)^{2}-F \quad \text { and } \quad \pi_{L}^{(O, I)}=\left(\frac{a-2 c_{L}+c}{3}\right)^{2} .
$$

Then, given the belief, the high cost type by deviation would get

\footnotetext{
${ }^{8}$ As is well known, in a Perfect Bayesian equilibrium the off-the-equilibrium belief can be arbitrary and there is no restriction imposed on it by this equilibrium notion. Here the off-the-equilibrium belief $\mu(H \mid I)=1$ is driving the result that both types firm 2 would choose outsourcing in equilibrium. One can generate infinitely many equilibria involving outsourcing by simply altering the off-the-equilibrium belief here.

Note that this off-the-equilibrium belief is sufficient to establish the existence of pooling equilibrium for all $F<$ $\underline{F}^{O O}$, where both types of firm 2 will engage in outsourcing. Now the question is whether this pooling equilibrium $\overline{\text { is }}$ in some sense reasonable, e.g. does it survive the "intuitive criterion", suggested by Cho and Kreps (1987) which uses an "equilibrium domination" argument? Consider an unexpected deviation to in-house production made by the low cost type firm 2 with the hope that firm 1 revises its off-the-equilibrium belief in favour of the low cost type firm 2 conditional on deviation. This change in belief would also attract the high cost type firm 2 to deviate to in- house production and as a result the "intuitive criterion" would not have any bite in the given context. Therefore, the pooling equilibrium with the above off-the-equilibrium belief survives the "intuitive criterion."
} 


$$
\hat{\pi}_{H}^{(O, I)}=\left(\frac{a-2 c_{H}+c}{3}+\frac{c_{H}-c_{L}}{6}\right)^{2}
$$

Then given $F>0$, we have always $\hat{\pi}_{H}^{(O, I)}>\pi_{H}^{(O, I)}$, hence (Outsourcing, In-house) as a separating equilibrium cannot be sustained.

Finally, it may be mentioned that in this paper our purpose is not to characterize all possible equilibria under incomplete information. We may, however, note that when the fixed cost of outsourcing is above a critical level, a pooling equilibrium in which both types of firm 2 produce inputs in-house can always be sustained with some off-the-equilibrium beliefs. ${ }^{9}$

\section{Welfare analysis}

In this section we discuss the welfare implications of outsourcing under incomplete information, comparing the social utility under incomplete information vis-à-vis that under complete information.

Given that nature determines the type of firm 2, under complete information there will be no outsourcing. However, under incomplete information when the fixed cost associated with outsourcing is at an intermediate level, the $L$ type firm 2 will outsource inputs and the $H$ type will produce in-house (vide Proposition 2). Hence in such a situation the outcome in the final goods market will be exactly similar to the case of complete information depending on the type of firm 2. Since individual firm's output as well as the industry output will remain the same, consumers' surplus will remain unchanged. Similarly, firm 1 and the $H$ type firm 2's profits will remain unchanged but the $L$ type firm 2's profit will fall to the extent of fixed cost of outsourcing. Therefore, when evaluated ex ante, i.e. before the realization of nature's choice, while consumers' surplus is not affected, the expected industry profit and hence the expected overall welfare will unambiguously fall under incomplete information with a separating outsourcing equilibrium compared to the case of complete information.

\footnotetext{
${ }^{9}$ Note that existence of various equilibria in our model depend on parameter values, and in particular, on $F$. If we rank the relevant cut-offs on $F$, we have : $\underline{F}^{O O}<\underline{F}^{O}<\bar{F}^{O}$. We then have a pooling equilibrium on outsourcing for all $F<\underline{F}^{O O}$, a separating equilibrium for all $F \in\left(F^{O}, \bar{F}^{O}\right)$ and a pooling equilibrium on in-house production for $F>\bar{F}^{O}$. Therefore, when $F \in\left(\underline{F}^{O O}, \underline{F}^{O}\right)$, a randomization will occur between pooling and separating equilibrium.
} 
On the other hand, when the fixed cost is below a critical level, under incomplete information both types of firm 2 will outsource inputs in equilibrium (vide Proposition 3). Then it is easy to show that compared to the case of complete information, industry output under incomplete information will fall (rise) if firm 2 is of $H(L)$ type. Therefore, ex post, consumers will benefit (lose) if $L(H)$ is the realization. Interestingly, expected consumers' welfare under incomplete information evaluated before the realization of nature's choice, will unambiguously rise. On the other hand, the expected total producers' surplus, as well as overall welfare diminishes as compared to complete information regime.

Thus, the welfare implication for the separating outsourcing equilibrium is straightforward and it is only the additional cost of outsourcing that matters. For the case of pooling outsourcing equilibrium, the welfare result is stated in the following proposition.

Proposition 4: Under incomplete information with a pooling outsourcing equilibrium, consumers' surplus rises, industry profit falls but the overall welfare, defined as the sum of consumers' surplus and industry profit, goes down unambiguously.

The results are derived in Appendix B. ${ }^{10}$ The intuition is the following. The inefficiency of production increases under incomplete information due to a higher production by the $\mathrm{H}$ type of firm 2 and a lower production by the $L$ type. This reduces the profit. On the other hand, the expected industry output under pooling is the same as that under complete information, but the variation goes up as the output is lower in $\mathrm{H}$ state and higher in $\mathrm{L}$ state. Due to this mean preserving spread nature of output changes and the quadratic functional form of consumer surplus, under pooling equilibrium the consumer surplus goes up. Overall welfare however falls as profit decreases more than the increase in consumer surplus.

\section{Summary of the results}

Suppose that in a quantity setting duopoly with asymmetric information firms have the option of choosing between outsourcing and in-house input production, and that the firm with private information is either high cost or low cost. Then in equilibrium either only the low cost type,

\footnotetext{
${ }^{10}$ Assuming symmetric distribution of realization of firm's costs, Shapiro (1986) had earlier shown that welfare under Bayesian Nash equilibrium falls unambiguously compared to the case of sharing private information. Sharing private information is equivalent to our case of complete information.
} 
or both types of firm will opt for outsourcing. This result is surprising given the fact that the firms would never be involved in outsourcing under complete information. Under incomplete information, equilibria where both types outsource arise when the fixed cost associated with outsourcing activity is below a critical level. When the fixed cost is neither too small nor too large, a separating equilibrium exists in which the low cost type outsources inputs from the input market and the high cost type produces inputs in-house. However, outsourcing by only the high cost type can never occur in equilibrium. Finally, we have provided a discussion on welfare comparison between the regimes with complete and incomplete information, and have shown that the consumers gain and producers loose under incomplete information. But the overall welfare defined as the sum of consumers' surplus and profits falls under incomplete information compared to complete information. 


\section{Appendix}

Appendix A: Proof of the results underlying Eqn (8):

If $\mathrm{H}$ deviates and chooses 'outsourcing', given the belief firm 1 will presume firm 2 to be low cost type, hence will chooses a quantity, $X_{1}=\frac{a-2 c+c_{L}}{3}$. Against this, H's best response will be $X_{2}=\frac{a-X_{1}-c_{H}}{2}=\frac{a-2 c_{H}+c}{3}+\frac{c_{H}-c_{L}}{6}$. Then $\hat{\pi}_{H}^{(I, O)}=\left(X_{2}\right)^{2}-F$.

Similarly, if L deviates and chooses 'in-house', given the belief firm 1 will presume firm 2 to be the high cost type, hence will choose a quantity, $X_{1}=\frac{a-2 c+c_{H}}{3}$. Against this, L's best response will be $X_{2}=\frac{a-X_{1}-c_{L}}{2}=\frac{a-2 c_{L}+c}{3}-\frac{c_{H}-c_{L}}{6}$ and the corresponding profit is $\left(\frac{a-2 c_{L}+c}{3}-\right.$ $\left.\frac{c_{H}-c_{L}}{6}\right)^{2}$

\section{Appendix B: Proof of Proposition 4}

First consider complete information case. Let $X_{i}^{t}$ be the output of firm $i$ under complete information when firm 2's type is $t ; t=H, L$ and $i=1,2$. Then we have, $X_{1}^{t}=\frac{a-2 c+c_{t}}{3}$ and $X_{2}^{t}=\frac{a-2 c_{t}+c}{3}$. Hence industry output under complete information when firm 2 is of $t$ type is, $Y^{t}=\frac{2 a-c-c_{t}}{3}$. Therefore, the expected consumer surplus (i.e., before realization of nature's outcome) is:

$$
S=\frac{1}{2}\left[\theta\left(Y^{H}\right)^{2}+(1-\theta)\left(Y^{L}\right)^{2}\right]
$$

When firm 2 is of type $t$, industry profit is: $\Pi^{t}=\left(X_{1}^{t}\right)^{2}+\left(X_{2}^{t}\right)^{2}$. Therefore, expected industry profit is:

$$
\Omega=\theta \Pi^{H}+(1-\theta) \Pi^{L}
$$

Hence the overall welfare under complete information is: $=S+\Omega$.

Now consider polling equilibrium under incomplete information. The outputs of firm 1 and two types of firm 2 in equilibrium are:

$$
\begin{aligned}
& \widehat{X_{1}}=X_{1}^{H}-2 \gamma=X_{1}^{L}+2 \delta \\
& \widehat{X_{2}^{H}}=X_{2}^{H}+\gamma \text { and } \widehat{X_{2}^{L}}=X_{2}^{L}-\delta
\end{aligned}
$$


where,

$$
\gamma=\frac{(1-\theta)\left(c_{H}-c_{L}\right)}{6} \text { and } \delta=\frac{\theta\left(c_{H}-c_{L}\right)}{6}
$$

Then industry output under pooling equilibrium when realization is $\mathrm{H}$ or $\mathrm{L}$,

$$
\widehat{Y^{H}}=Y^{H}-\gamma \text { and } \widehat{Y^{L}}=Y^{L}+\delta
$$

Clearly, $\widehat{Y^{H}}<Y^{H}$ and $\widehat{Y^{L}}>Y^{L}$.

Then the expected consumer surplus under this situation is:

$$
\hat{S}=\frac{1}{2}\left[\theta\left(\widehat{Y^{H}}\right)^{2}+(1-\theta)\left(\widehat{Y^{L}}\right)^{2}\right]=S+\frac{5}{72} \theta(1-\theta)\left(c_{H}-c_{L}\right)^{2}
$$

Hence, $\hat{S}>S$.

Assume $F=0$. Then industry profit when firm 2's type is H,

$$
\begin{aligned}
\widehat{\Pi^{H}} & =\left(X_{1}^{H}-2 \gamma\right)^{2}+\left(X_{2}^{H}+\gamma\right)^{2} \\
& =\Pi^{H}+5 \gamma^{2}+2 \gamma\left(X_{2}^{H}-2 X_{1}^{H}\right)
\end{aligned}
$$

and that when firm 2's type is L,

$$
\begin{aligned}
\widehat{\Pi^{L}} & =\left(X_{1}^{L}+2 \delta\right)^{2}+\left(X_{2}^{L}-\delta\right)^{2} \\
& =\Pi^{L}+5 \delta^{2}+2 \delta\left(2 X_{1}^{L}-X_{2}^{L}\right)
\end{aligned}
$$

Then the expected profit under pooling equilibrium is.

$$
\widehat{\Omega}=\theta \widehat{\Pi^{H}}+(1-\theta) \widehat{\Pi}^{L}=\Omega-\frac{11}{36} \theta(1-\theta)\left(c_{H}-c_{L}\right)^{2}
$$

Hence, $\widehat{\Omega}<\Omega$.

Finally, welfare under pooling equilibrium is,

$$
\widehat{W}=\hat{S}+\widehat{\Omega}=W-\frac{17}{72} \theta(1-\theta)\left(c_{H}-c_{L}\right)^{2}
$$

Hence, $\widehat{W}<W$ even when $F=0$. 


\section{References}

Arya, A., Mittendorf, B. and Sappington, D.E.M. (2008), "The make-or-buy decision in the presence of a rival: strategic outsourcing to a common supplier", Management Science 54, $1747-1758$.

Beladi, H., Marjit, S. and Yang, L. (2012), “Outsourcing: volume and composition of R\&D”, Review of International Economics 20, 828-840.

Buehler, S. and Haucap, J. (2006), "Strategic outsourcing revisited", Journal of Economic Behaviour and Organization 61, 325-338.

Chen, Y. (2011), "Strategic sourcing for entry deterrence and tacit collusion", Journal of Economics 102, 137 - 156.

Cho, I. K. and Kreps, D. M. (1987), “Signaling games and stable equilibria”, Quarterly Journal of Economics, 102, 179-221.

Gibbons, R. (1992), Game Theory for Applied Economists, Princeton University Press, Princeton.

Kabiraj, T. and Sinha, U. B. (2014), "Strategic outsourcing with technology transfer under Cournot competition”, Economics Bulletin 34, 1133-1140.

Kabiraj, T. and Sinha, U. B. (2016), "Strategic outsourcing with technology transfer under price competition", International Review of Economics and Finance 44, 281-290.

Lewin, A. and Couto, V., (2007), Next generation offshoring: the globalization of innovation, Durham. NC: Duke University Center of International Business Education and Research (CIBER).

Lewin, A.Y. and Peeters, C. (2006), "Offshoring work: Business hype or the onset of fundamental transformation?", Long Range Planning 39, 221-239.

Lewin, A.Y., Massini, S. and Peeters, C. (2009), "Why are companies offshoring innovation? The emerging global race for talent”, Journal of International Business Studies 40, 901-925. Manning, S. (2013), "New Silicon Valleys or a new species? Commoditization of knowledge work and the rise of knowledge services clusters", Research Policy 42, 379-390. 
Manning, S., Massini, S. and Lewin, A.Y. (2008), “A dynamic perspective on next generation offshoring: the global sourcing of science and engineering talent", Academy of Management Perspectives 22, 35-54.

Marjit, S. and Mukherjee, A. (2008), "International outsourcing and R\&D: long run implications for consumers", Review of International Economics 16, 1010-1022.

Pack, H. and Saggi, K. (2001), "Vertical Technology Transfer via International Outsourcing”, Journal of Development Economics 65, 389-415.

Shapiro, C. (1986), "Exchange of cost information in oligopoly", Review of Economic Studies 53, pp. 433-446.

Shy, O. and Stenbacka, R. (2003), "Strategic outsourcing” Journal of Economic Behaviour and Organization 50, 203-224.

Sinha, U. B. (2016), "Economies of scale and (non)existence of strategic outsourcing in Cournot duopoly", Economics Bulletin 36, 1260-66. 